\title{
Infection, atherothrombosis and thromboembolism beyond the COVID-19 disease: what similar in physiopathology and researches
}

\author{
Michele Correale $^{1}\left[\right.$ (D) Lucia Tricarico ${ }^{2} \cdot$ Martino Fortunato $^{2} \cdot$ Giuseppe Dattilo $^{3} \cdot$ Massimo lacoviello $^{2}$. \\ Natale Daniele Brunetti ${ }^{2}$
}

Received: 14 September 2020 / Accepted: 7 December 2020 / Published online: 15 January 2021

(c) The Author(s), under exclusive licence to Springer Nature Switzerland AG part of Springer Nature 2021

\begin{abstract}
The recent Sars-Cov-2 pandemic (COVID-19) has led to growing research on the relationship between thromboembolism and Sars-Cov-2 infection. Nowadays, endothelial dysfunction, platelet activation, coagulation, and inflammatory host immune response are the subject of extensive researches in patients with COVID-19 disease. However, studies on the link between microorganisms or infections and thrombotic or thromboembolic events met fluctuating interest in the past. We, therefore, aimed to briefly summarize previous evidence on this topic, highlighting common points between previous data and what experienced today with SARS-COV2 infections.
\end{abstract}

Keywords Coronavirus disease 2019 (COVID-19) · Severe acute respiratory syndrome coronavirus 2 (SARS-CoV-2) . Thromboembolism · Thrombosis

\section{Introduction}

Infections may increase the risk of cardiovascular events. Respiratory infections are associated with an increased risk of thrombotic vascular disease such as myocardial infarction, ischemic stroke and venous thrombosis [1]. Up to one-third of patients hospitalized with pneumococcal pneumonia may be affected by major adverse cardiac events during or after pneumonia [2]. An increased risk of cardiovascular mortality has been observed after pneumonia [3]. Apparently, for every infection type, an increased likelihood of venous thromboembolism (VTE) may be observed. In subjects with pneumonia, either due to S. Pneumoniae or influenza virus, VTE occurrence was even higher $[4,5]$. Furthermore, lung infection is complicated by platelet aggregation [6] and

Michele Correale

opsfco@tin.it

1 Cardiology Unit, University Hospital Policlinico Riuniti, Viale Pinto1, 71100 Foggia, Italy

2 Department of Medical and Surgical Sciences, University of Foggia, Foggia, Italy

3 Department of Clinical and Experimental Medicine, University of Messina, Messina, Italy clotting system activation (up-regulation of tissue factor and down-regulation of activated protein C) [3]. Thromboprophylaxis in critically ill patients with acute infections is recommended [7], mainly in the case of pulmonary infections.

The recent severe acute respiratory syndrome coronavirus 2 (Sars-CoV-2) pandemic, characterized in many cases by severe acute respiratory syndrome and thrombotic complications, has boosted research on the relationship between thromboembolism and Sars-CoV-2 infection.

We have already reported on thrombotic complications and thromboembolism in coronavirus disease-19 (COVID19) [8], emphasizing the fundamental role of the endothelial dysfunction, platelet activation, clotting system and inflammatory host immune response. However, studies on the link between microorganisms or infections and thrombotic or thromboembolic events met fluctuating interest in the past (Table 1). We, therefore, aimed to briefly summarize previous evidence on this topic, highlighting common points between previous data and what experienced today with SARS-COV2 infections. 


\section{Methods}

We performed a systematic research using Embase and PubMed, using the keywords and mesh terms relative to the infection and thromboembolism or thrombotic complications. Boolean operators 'AND', 'OR', 'NOT' were used where appropriate. Inclusion criteria were: (a) publication between January 2000 and June 2020, (b) epidemiological relevance, and (c) clinical impact. We excluded publications that: (a) were not directly focused on thrombosis or thrombotic complications, (b) provided information overlap with larger studies or more recent articles. The use of a combination of the inclusion criteria provided the most recent information.

\section{Infection and thromboembolism}

Generally, infection and immobilization had an addictive effect on the thromboembolic risk, and this effect is present in COVID-19 patients, too. However, hospitalization with infection is a strong thromboembolic stimulus also in nonimmobilized patients [9].

SARS-CoV-2 is frequently associated with coagulopathy with possible large vessel thrombosis and major thromboembolic complications, including pulmonary embolism [10]. Beyond the association between thromboembolism and COVID-19 disease [11-13], several etiologic agents have been correlated with thromboembolism. A higher incidence of venous thromboembolism (VTE) in patients with HIV infection has been described [14]. Interestingly, HIV patients may develop VTE and precapillary pulmonary hypertension (PH) [15]. HIV-PH is included in group
$1 \mathrm{PH}$ group classification and need a multidisciplinary approach [16]. Thrombotic complications in COVID19 patients may also need a similar multidisciplinary approach (pneumologists, cardiologists, infectious disease specialists, intensivists). The physiopathology of $\mathrm{PH}$ is characterized by endothelial dysfunction. The endothelial function in patients with cardiovascular diseases may be hampered by the SARS-CoV-2 infection: inflammatory cytokines may increase the expression of adhesion molecules and further inflammation activation, resulting in procoagulant changes, endothelial activation and, finally, in worsening microvascular perfusion [17].

Restoring nitric oxide may contribute to pulmonary vasodilatation and may be a potential treatment for SARSCoV-2. In patients with pulmonary arterial hypertension (PAH) (group 1 of the PH classification), progressive disease with thrombotic findings, characterized by increased pulmonary vascular pressure and right heart failure, specific pulmonary vasodilators are strongly recommended [18].

A special condition occurs in patients with $\mathrm{HCV}$ and cirrhosis of various etiologies, being at increased risk of several types of thromboembolic events. Porto-pulmonary hypertension $(\mathrm{PoPH})$, a relatively common pulmonary vascular complication of advanced liver disease [19], is also included in the group 1 of the $\mathrm{PH}$ classification and need specific pulmonary vasodilators and a multidisciplinary approach.

\section{Infection in atherothrombosis}

Infection and products of the endogenous microbiome might modulate atherosclerosis and its complications, either directly or indirectly, by eliciting local and systemic

Table 1 Infections with thrombotic and throemboembolic complications and possible similarities to those of infection SARS-CoV-2

\begin{tabular}{|c|c|c|}
\hline Infectious agent & Thrombotic or thromboembolic complications & Therapeutic possibilities \\
\hline HIV infection & $\begin{array}{l}\text { VTE } \\
\text { Pulmonary hypertension } \\
\text { Endothelial dysfunction } \\
\text { Inflammation }\end{array}$ & $\begin{array}{l}\text { Anticoagulants } \\
\text { Pulm. vasodilatator } \\
\text { Anti-inflammatory drugs }\end{array}$ \\
\hline HCV infection & $\begin{array}{l}\text { VTE } \\
\text { Pulmonary hypertension }\end{array}$ & $\begin{array}{l}\text { Anticoagulants } \\
\text { Pulm. vasodilatator }\end{array}$ \\
\hline Respiratory infections & $\begin{array}{l}\text { Myocardial Infarction } \\
\text { Ischemic stroke } \\
\text { Venous thrombosis }\end{array}$ & $\begin{array}{l}\text { Anticoagulants } \\
\text { Thrombolysis } \\
\text { Antiaggregants }\end{array}$ \\
\hline Pneumococcal pneumonia & $\begin{array}{l}\text { Major adverse cardiac events (total death, Myocardial infarction, } \\
\text { ischemic stroke, HF hospitalization) }\end{array}$ & Antiaggregants \\
\hline S. pneumoniae or flu pneumonia & $\begin{array}{l}\text { VTE } \\
\text { Atherosclerotic events }\end{array}$ & $\begin{array}{l}\text { Anticoagulants } \\
\text { Antiaggregants }\end{array}$ \\
\hline Chlamydia pneumoniae & Coronary artery disease & Antibiotic therapy \\
\hline Helicobacter pylori & Coronary artery disease & Antibiotic therapy \\
\hline Mycoplasma pneumoniae & Coronary artery disease & Antibiotic therapy \\
\hline
\end{tabular}

$H I V$ human immunodeficiency virus, $V T E$ venous thromboembolism, $H C V$ hepatitis C virus, $H F$ heart failure, $P u l m$ pulmonary, $S$ streptococcus 
responses. [20] Previous studies have identified markers of nucleic acid and antigens of viral and bacterial pathogens within atherosclerotic plaques, allowing to speculate that infection could play a role in precipitating atherosclerotic events. Furthermore, bacterial products can stimulate vascular inflammation $[21,22]$ and Gram-negative bacterial endotoxin may strongly elicit inflammatory responses from endothelial cells. Chronic infections, not in the vascular district, could provide a stimulus that contributes to inflammatory burden [23]. The body responses induced by the infection may precipitate complications of atherosclerosis or enhance their consequences because acute consequences of bacterial infections can increase myocardial oxygen requirements, decrease oxygen availability, promote clot formation, and impair the endogenous fibrinolytic system. In particular, during sepsis, tachycardia and fever can lead to a hyperkinetic state that increase oxygen demands and may predispose to acute coronary syndromes; in case of patients with coronary heart disease, the decreased oxygen supply due to hypoxemia can worsen myocardial ischemia.

Increased rates of cardiovascular events and thrombosis in patients with pneumonia have shown how respiratory infections can affect clinical outcomes [3]; previous observational and pathophysiologic evidence supports the association between recent respiratory infections [24-27] or influenza [28] and atherosclerotic events. It was also demonstrated that pneumonia may accelerate the progression of atherosclerosis [25]. A randomized open-label study showed that acetyl-salicylic acid may be beneficial in the reduction of acute coronary syndrome complications and cardiovascular mortality in patients with pneumonia [29]. Different viruses and bacteria may be associated with atherosclerotic diseases. Previous data support the hypothesis that a previous influenza virus infection may be associated with acute myocardial infarction [30, 31]. Chlamydia pneumoniae infection was considered a risk factor for atherosclerosis and coronary heart disease (CAD) [32] The level of Chlamydia pneumoniae and Helicobacter pylori-specific IgG antibodies have been found elevated in CAD patients; their presence has been associated with the development of the CAD and correlated to cholesterol levels. Chlamydia pneumoniaespecific IgG were significantly correlated with hsCRP, suggesting an important role of these organisms in the development of CAD by altering lipid profile and induction of inflammation [33]. Previous studies showed the presence of Chlamydia pneumoniae, chlamydial antigens or nucleic acid in atherosclerotic plaques [34]. None of the known risk factors for cardiovascular disease was significantly associated with Chlamydia pneumoniae seropositivity IgG [35]. Mycoplasma pneumonia patients exhibited a 37\% increase in the risk of subsequently developing ACS [36].

However, trials with antibiotics did not reduce the recurrence of cardiovascular events. Treatment with macrolides such as azithromycin, or fluoroquinolones or gatifloxacin showed no reduction of cardiovascular events in the tested patients [37]. Vaccination also has not yet achieved the desired results in reducing cardiovascular events in [20].

Coronary thrombosis [38], coronary stent thrombosis [39], acute myocardial infarction [40] and failed fibrinolytic therapy [41] have been reported in COVID-19 patients. However, SARS-CoV-2 has not been identified in coronary plaque so far. Mechanisms linking SARS-CoV-2 to plaque instability can be hypothesized. Immune-mediated inflammation may play a key role in the pathogenesis of COVID19 and persistent anti-viral immune response may elicit an important hyperinflammatory response (like a cytokine storm) causing cells damage. Other suspected factors are the hypercoagulability and the development of coronary microvascular thrombosis [42], the diffuse endothelial injury and 'endothelitis' as a direct consequence of SARS-CoV-2 viral involvement and/or resulting from host inflammatory response [43], and, the same inflammation causing coronary plaque rupture.

Despite a widespread use of broad-spectrum antibacterials in COVID-19 patients [44], in the absence of documented cases of bacterial coinfections, preliminary data show that early administered antibiotics in COVID-19 patients do not seem to significantly affect mortality or delay hospital-acquired infections in critically ill patients [45]. Instead, anti-inflammatory interventions such as anticytokine therapy and colchicine have shown some efficacy in CAD. The Canakinumab Anti-inflammatory Thrombosis Outcomes Study (CANTOS) showed that reducing inflammation by administering an anti-IL-1 beta antibody in men and women who had a prior heart attack and residual inflammation despite standard-of-care therapy can reduce recurrent events [46, 47]. The anti-inflammatory therapy yielded a significant $15 \%$ reduction in the primary endpoint of "hard" major adverse cardiovascular events. Anticytokine therapy (IL-6 inhibitors, IL-1 inhibitors, anti-TNF- $\alpha$ agents, corticosteroids) and colchicine have been tested also for SARSCoV-2 [48]. Further studies are needed to establish the efficacy of these drugs in COVID-19 patients.

According to Libby et al. [20], inflammation, immunity, and infection can contribute to atherogenesis or trigger atherosclerotic events without diminishing the role of classic risk factors; such factors should be rather considered as adjunctive to classic pathobiological processes than alternative (Fig. 1). COVID19 patients are frequently characterized by increased inflammation, pro-thrombotic state, and coagulopathy with important interactions between these systems [49]. Also in COVID-19 infection, inflammation response and immunity can contribute to atherogenesis or trigger atherosclerotic events, making the pathobiological process very complex and perhaps causing variability in antithrombotic or anticoagulant therapy effect. Recently, growing interest in intestinal microflora in 


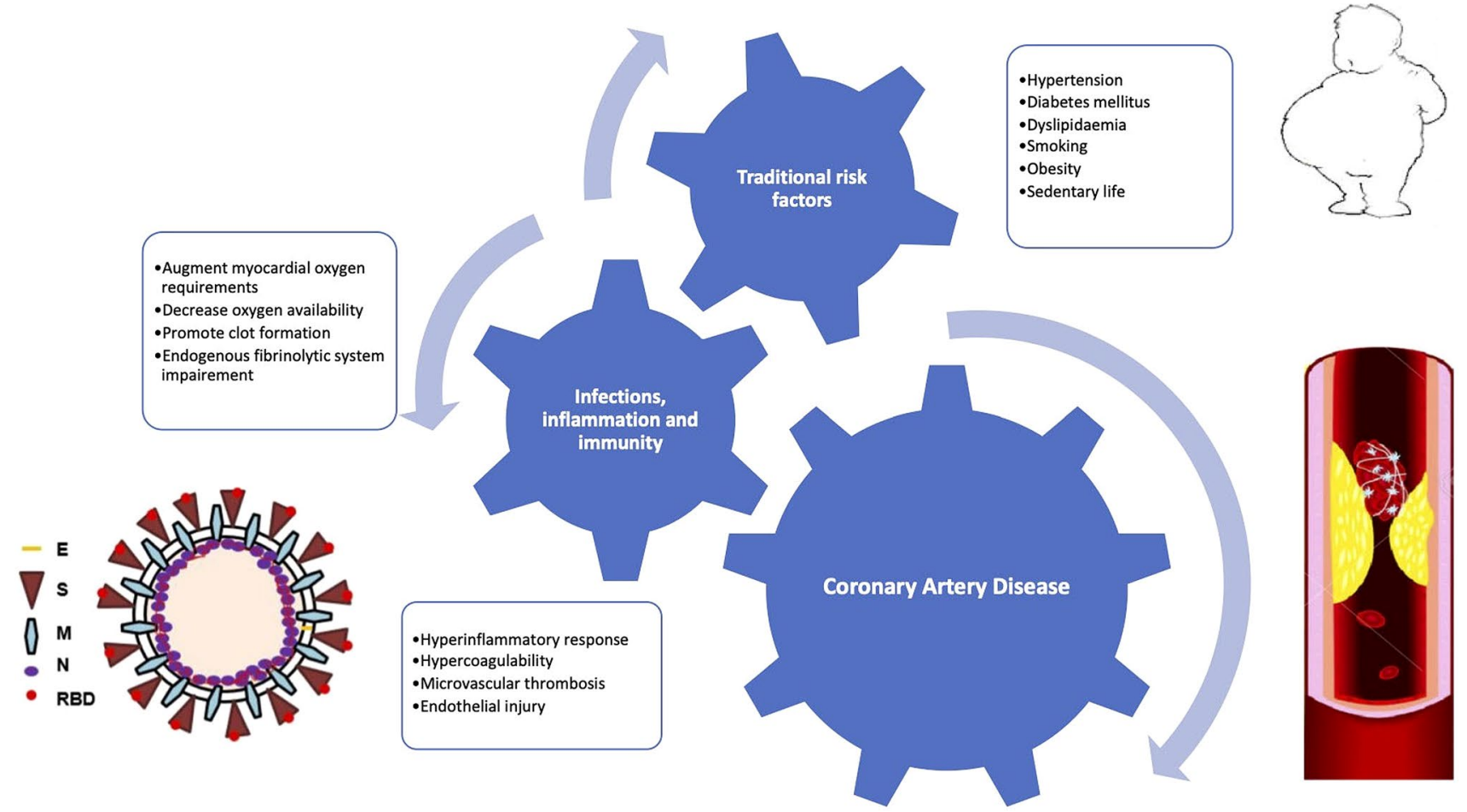

Fig. 1 Infection, inflammation and immunity contribute to atherogenesis without replacement of traditional risk factors. Infection, inflammation and immunity contribute to atherogenesis or trigger athero-

the cardiometabolic disease was reported [50, 51]. Bacteria in the gastrointestinal tract provides a rich source of bacterial products such as endotoxins. In cases of the impaired epithelial barrier, these bacterial products might convey into the circulation and provide another source of inflammatory stimuli. Gut microbiota is considered as an endocrine organ with metabolic capacity to produce multiple messengers that through circulation can reach distant districts. Recently, Carnevale et al. [52] hypothesized that, in particular, conditions (as in leaky gut), a penetration of LPS produced by Escherichia coli through the bloodstream into the coronary bed, where it may exert a thrombogenic effect, leading to the acute coronary syndrome.

\section{Evidence synthesis}

Infections are independent risk factors for venous thromboembolism and should be considered as potential indications for venous thromboembolism prophylaxis [53]. Microbial products, increased inflammation and pro-thrombotic state can promote the thromboembolism in several infections. While direct infection may not be a common driver of atherogenesis, remote infections and bacterial products from extra-vascular infections may promote atherosclerosis. Acute bacterial infections such as Gram-negative sepsis can sclerotic events without diminishing the role of classic risk factors but they are an addition to the classic pathobiological process than a replacement of the specific agents

precipitate type 2 acute coronary syndromes. Thrombotic complications due to increased inflammation, pro-thrombotic state, and endothelial dysfunction were detected in the novel disease (Covid-19) due to SARS-CoV-2 infection, responsible for the recent pandemic. Serious coagulation abnormalities may occur in several critically ill COVID-19 patients.

\section{Conclusions}

Infections may influence several diseases, either directly or indirectly, acutely or chronically. Pneumonia may accelerate the progression of atherosclerosis. In patients with pneumonia, increased rates in cardiovascular events and thrombosis have been demonstrated. A novel disease COVID-19 due to SARS-CoV-2 infection is characterized by coagulation abnormalities and inflammation with thrombotic and thromboembolism complications. Studies on the link between microorganisms or infections and thrombotic or thromboembolic events met fluctuating interest in the past. Looking back to what is known and what is currently discovered in SARS-CoV-2 infection, could be of help in the development of new therapies for the prevention of thrombotic complication in COVID-19. 
Funding No funding was received by authors.

\section{Compliance with ethical standards}

Conflict of interest Authors have no potential conflict of interest to disclose.

Ethical standards The paper was written according to ethical standards principles.

Statement of human and animal rights This is a review paper. No human or animal experiments have been conducted.

Informed consent Not applicable.

\section{References}

1. Warren-Gash C, Blackburn R, Whitaker H et al (2018) Laboratory-confirmed respiratory infections as triggers for acute myocardial infarction and stroke: a self-controlled case series analysis of national linked datasets from Scotland. Eur Respir J 51:1701794

2. Reyes LF, Restrepo MI, Hinojosa CA et al (2017) Severe pneumococcal pneumonia causes acute cardiac toxicity and subsequent cardiac remodeling. Am J Respir Crit Care Med 196:609-620

3. Violi F, Cangemi R, Calvieri C (2014) Pneumonia, thrombosis and vascular disease. J Thromb Haemost 12:1391-1400

4. Chen YG, Lin TY, Huang WY et al (2015) Association between pneumococcal pneumonia and venous thromboembolism in hospitalized patients: a nationwide population-based study. Respirology 20:799-804

5. Obi AT, Tignanelli CJ, Jacobs BN et al (2019) Empirical systemic anticoagulation is associated with decreased venous thromboembolism in critically ill influenza A H1N1 acute respiratory distress syndrome patients. J Vasc Surg Venous Lymphat Disord $7: 317-324$

6. Cangemi R, Casciaro M, Rossi E et al (2014) Platelet activation is associated with myocardial infarction in patients with pneumonia. J Am Coll Cardiol 64:1917-1925

7. Cook D, McMullin J, Hodder R et al (2001) Prevention and diagnosis of venous thromboembolism in critically ill patients: a Canadian survey. Crit Care 5:336-342

8. Casale M, De Fazio MG, Morabito C et al (2020) The thromboembolism in COVID-19: the unsolved problem. Panminerva Med. https://doi.org/10.23736/S0031-0808.20.03999-3

9. Grimnes G, Isaksen T, Tichelaar YIGV et al (2017) Acute infection as a trigger for incident venous thromboembolism: results from a population-based case-crossover study. Res Pract Thromb Haemost 2:85-92

10. Iba T, Levy JH, Levi M et al (2020) Coagulopathy of coronavirus disease 2019. Crit Care Med 48:1358-1364

11. Cui S, Chen S, Li X, et al (2020) Prevalence of venous thromboembolism in patients with severe novel coronavirus pneumonia. J Thromb Haemost.

12. Zhai Z, Li C, Chen Y, et al (2020) Prevention and treatment of venous thromboembolism associated with coronavirus disease 2019 infection: a consensus statement before guidelines. Thromb Haemost.

13. Casey K, Iteen A, Nicolini R et al (2020) COVID-19 pneumonia with hemoptysis: acute segmental pulmonary emboli associated with novel coronavirus infection. Am J Emerg Med 38:1544. e1-1544.e3
14. Rokx C, Howard JFB, Smit C et al (2020) Risk of recurrent venous thromboembolism in patients with HIV infection: a nationwide cohort study. PLoS Med 17:e1003101

15. Correale M, Palmiotti GA, Lo Storto MM et al (2015) HIVassociated pulmonary arterial hypertension: from bedside to the future. Eur J Clin Invest 45:515-528

16. Correale M, Montrone D, Lacedonia D et al (2012) Multiprofessional and intrahospital experience for diagnosis and treatment of pulmonary arterial hypertension. Monaldi Arch Chest Dis 78:205-209

17. De Lorenzo A, Escobar S, Tibiriçá E (2020) Systemic endothelial dysfunction: a common pathway for COVID-19, cardiovascular and metabolic diseases. Nutr Metab Cardiovasc Dis 30:1401-1402

18. Galiè N, Humbert M, Vachiery JL et al (2016) 2015 ESC/ERS guidelines for the diagnosis and treatment of pulmonary hypertension: the joint task force for the diagnosis and treatment of pulmonary hypertension of the European Society of Cardiology (ESC) and the European Respiratory Society (ERS): endorsed by: Association for European Paediatric and Congenital Cardiology (AEPC), International Society for Heart and Lung Transplantation (ISHLT). Eur Heart J 37:67-119

19. Correale M, Tricarico L, Leopizzi A et al (2020) Liver disease and heart failure. Panminerva Med 62:26-37

20. Libby P, Loscalzo J, Ridker PM et al (2018) Inflammation, immunity, and infection in atherothrombosis: JACC review topic of the week. J Am Coll Cardiol 72:2071-2081

21. Kol A, Libby P (1998) The mechanisms by which infectious agents may contribute to atherosclerosis and its clinical manifestations. Trends Cardiovasc Med 8:191-199

22. Kol A, Libby P (1999) Molecular mediators of arterial inflammation: a role for microbial products? Am Heart $\mathrm{J}$ 138:S450-S452

23. Sessa R, Pietro MD, Filardo $S$ et al (2014) Infectious burden and atherosclerosis: a clinical issue. World J Clin Cases 2:240-249

24. Clayton TC, Thompson M, Meade TW (2008) Recent respiratory infection and risk of cardiovascular disease: case-control study through a general practice database. Eur Heart J 29:96-103

25. Corrales-Medina VF, Alvarez KN, Weissfeld LA et al (2015) Association between hospitalization for pneumonia and subsequent risk of cardiovascular disease. JAMA 313:264-274

26. Restrepo MI, Reyes LF (2018) Pneumonia as a cardiovascular disease. Respirology 23:250-259

27. Ivey KS, Edwards KM, Talbot HK (2018) Respiratory syncytial virus and associations with cardiovascular disease in adults. J Am Coll Cardiol 71:1574-1583

28. Kwong JC, Schwartz KL, Campitelli MA et al (2018) Acute myocardial infarction after laboratory-confirmed influenza infection. N Engl J Med 378:345-353

29. Oz F, Gul S, Kaya MG et al (2013) Does aspirin use prevent acute coronary syndrome in patients with pneumonia: multicenter prospective randomized trial. Coron Artery Dis 24:231-237

30. Guan X, Yang W, Sun X et al (2012) Association of influenza virus infection and inflammatory cytokines with acute myocardial infarction. Inflamm Res 61:591-598

31. Pearce DC, McCaw JM, McVernon J et al (2017) Influenza as a trigger for cardiovascular disease: an investigation of serotype, subtype and geographic location. Environ Res 156:688-696

32. Sakurai-Komada N, Iso H, Koike KA et al (2014) Association between Chlamydophila pneumoniae infection and risk of coronary heart disease for Japanese: the JPHC study. Atherosclerosis 233:338-342

33. Al-Ghamdi A, Jiman-Fatani AA, El-Banna H (2011) Role of Chlamydia pneumoniae, helicobacter pylori and cytomegalovirus in coronary artery disease. Pak J Pharm Sci 24:95-101 
34. Monno R, Di Biase M, Costi A et al (2003) Chlamydia pneumoniae, atherosclerosis, and coronary disease. Ital Heart J Suppl 4:383-397

35. Monno R, Fumarola L, Trerotoli P et al (2010) Seroprevalence of Chlamydophila pneumoniae in ischaemic heart disease. New Microbiol 33:381-385

36. Chung WS, Hsu WH, Lin CL et al (2015) Mycoplasma pneumonia increases the risk of acute coronary syndrome: a nationwide population-based cohort study. QJM 108:697-703

37. Andraws R, Berger JS, Brown DL (2005) Effects of antibiotic therapy on outcomes of patients with coronary artery disease: a metaanalysis of randomized controlled trials. JAMA 293:2641-2647

38. Seif S, Ayuna A, Kumar A et al (2020) Massive coronary thrombosis caused primary percutaneous coronary intervention to fail in a COVID-19 patient with ST-elevation myocardial infarction. Catheter Cardiovasc Interv. https://doi.org/10.1002/ccd.29050

39. Hinterseer M, Zens M, Wimmer RJ et al (2020) Acute myocardial infarction due to coronary stent thrombosis in a symptomatic COVID-19 patient. Clin Res Cardiol. https://doi.org/10.1007/ s00392-020-01663-4

40. Harari R, Bangalore S, Chang E et al (2020) COVID-19 complicated by acute myocardial infarction with extensive thrombus burden and cardiogenic shock. Catheter Cardiovasc Interv. https ://doi.org/10.1002/ccd.28992

41. Lacour T, Semaan C, Genet T et al (2020) Insights for increased risk of failed fibrinolytic therapy and stent thrombosis associated with COVID-19 in ST-segment elevation myocardial infarction patients. Catheter Cardiovasc Interv. https://doi.org/10.1002/ ccd. 28948

42. Han H, Yang L, Liu R et al (2020) Prominent changes in blood coagulation of patients with SARS-CoV-2 infection. Clin Chem Lab Med 58:1116-1120

43. Varga Z, Flammer AJ, Steiger P et al (2020) Endothelial cell infection and endotheliitis in COVID-19. Lancet 395:1417-1418

44. Rawson TM, Moore LSP, Zhu N et al (2020) Bacterial and fungal co-infection in individuals with coronavirus: a rapid review to support COVID-19 antimicrobial prescribing. Clin Infect Dis 71:2459-2468. https://doi.org/10.1093/cid/ciaa530

45. Buetti N, Mazzuchelli T, Priore EL, et al (2020) Early administered antibiotics do not impact mortality in critically ill patients with COVID-19. J Infect

46. Ridker PM, Everett BM, Thuren T et al (2017) Antiinflammatory therapy with Canakinumab for atherosclerotic disease. N Engl J Med 377:1119-1131

47. Libby P (2017) Interleukin-1 beta as a target for atherosclerosis therapy: biological basis of CANTOS and beyond. J Am Coll Cardiol 70:2278-2289

48. Soy M, Keser G, Atagündüz P et al (2020) Cytokine storm in COVID-19: pathogenesis and overview of anti-inflammatory agents used in treatment. Clin Rheumatol 39:2085-2094. https:// doi.org/10.1007/s10067-020-05190-5

49. Henry BM, Vikse J, Benoit S et al (2020) Hyperinflammation and derangement of renin-angiotensin-aldosterone system in COVID-19: a novel hypothesis for clinically suspected hypercoagulopathy and microvascular immunothrombosis. Clin Chim Acta 507:167-173

50. Aron-Wisnewsky J, Clement K (2016) The gut microbiome, diet, and links to cardiometabolic and chronic disorders. Nat Rev Nephrol 12:169-181

51. Tang WH, Kitai T, Hazen SL (2017) Gut microbiota in cardiovascular health and disease. Circ Res 120:1183-1196

52. Carnevale R, Sciarretta S, Valenti V et al (2020) Low-grade endotoxaemia enhances artery thrombus growth via Toll-like receptor 4: implication for myocardial infarction. Eur Heart J 41:31563165. https://doi.org/10.1093/eurheartj/ehz893

53. Cohoon KP, Ashrani AA, Crusan DJ et al (2018) Is infection an independent risk factor for venous thromboembolism? A population-based, case-control study. Am J Med 131:e2

Publisher's Note Springer Nature remains neutral with regard to jurisdictional claims in published maps and institutional affiliations. 